\title{
Diyarbakır İli Bazı Kiraz Bahçelerinde Bulunan Zararlı ve Faydalı böcek Türleri ile Bazı Önemli Zararlı Türlerin Doğada Görülme Zamanı
}

\author{
Mehmet Kaplan ${ }^{1 *}$ \\ ${ }^{1}$ Dicle Üniversitesi, Ziraat Fakültesi, Diyarbakır, Türkiye (ORCID: 0000-0002-2495-8075)
}

(İlk Geliş Tarihi 20 Eylül 2019 ve Kabul Tarihi 22 Ekim 2019)

(DOI: 10.31590/ejosat.622720)

ATIF/REFERENCE: Kaplan, M. (2019). Diyarbakır İli Bazı Kiraz Bahçelerinde Bulunan Zararlı ve Faydalı böcek Türleri ile Bazı Önemli Zararlı Türlerin Doğada Görülme Zamanı. Avrupa Bilim ve Teknoloji Dergisi, (17), 283-289.

$\ddot{\mathbf{O z}}$

Bu çalışma, 2015-2016 yılları arasında Diyarbakır ili kiraz alanlarındaki fitofag ve faydalı türler ile bazı önemlilerin doğada görülme zamanı belirlemek amacıyla yürütülmüştür. Örneklemelerde kiraz bahçelerinde ağaç dallarına yapılan darbe yöntemi yanı sıra türlere özgü eşeysel çekici tuzaklar yanı sıra çukur ve şaraplı besi tuzakları kullanılmıştır.

Çalışma sonuçlarına göre, kiraz bahçelerinde fitofag türlerden 28 böcek ve 1 akar ile genel predatör ve parazitoitlerden olan 14 faydalı böcek türü saptanmıştır. Saptanan zararlı türlerden Archips rosanus L., Rhagoletis cerasi Linnaeus, Tropinota hirta Poda,, Stephanitis pyri Fabricius, Myzus cerasi F., Capnodis tenebrionis L., Scolytus rugulosus Müller ve Tetranychus urticae Koch.'’un ekonomik yönden zararlı olduğu gözlenmiştir. Bunun birlikte Coccinella semptempunctata L., Synharmonia conglobata L., Scymnus pallipediformis Gunther, Metasyrphus corollae Fabricius ve Chrysoperla carnea (Stephens)'nın Diyarbakır ili Kiraz ağaçlarında en fazla görülen yararlı türler olarak belirlenmiştir.

Anahtar Kelimeler: Kiraz zararlıları, Doğal düşmanlar, Survey, Diyarbakır.

\section{Phytophagous and beneficial species on some cherry orchards, time to see some important species in nature in Diyarbakır Province}

\begin{abstract}
The study was conducted between 2015 and 2016 years, with the purpose of determining the phytophage and beneficial species in cherry orchards and to determine of occurence time in nature some of important pests in Diyarbakır provinces.

At the end of the study, 28 insects and 1 mite species were found as phytophagous and 14 predator and 1 parasitoid species were found as beneficial species.Determined pests, Archips rosanus L., Rhagoletis cerasi Linnaeus, Tropinota hirta Poda,, Stephanitis pyri Fabricius, Myzus cerasi F., Capnodis tenebrionis L., Scolytus rugulosus Müller and Tetranychus urticae Koch were also observed. In addition, the predators, Coccinella semptempunctata L., Synharmonia conglobata L., Scymnus pallipediformis Gunther, Metasyrphus corollae Fabricius and Chrysoperla carnea Stephens being the most encountered were observed in these provinces as well.
\end{abstract}

Key words: Cherry pests, Natural enemies, Survey, Diyarbakır,

\footnotetext{
*Sorumlu Yazar: Dicle Üniversitesi, Ziraat Fakültesi, Diyarbakır, Türkiye, ORCID: 0000-0002-2495-8075, mehmetkaplan1971@ hotmail.com
} 


\section{Giriş}

Kiraz, lezzetli bir meyve olmasının yanında, besin değeri çok yüksek olan bir meyve olması yanısıra Ayrıca, gerek üretim ve gerekse pazarlama aşamasında yoğun işgücünün kullanımı ile geniş istihdam olanakları yaratması, dış satımda önemli döviz getirisi nedeniyle ülke ekonomisi bakımından büyük önem taşımaktadır (Kaplan, 2019). Ülkemiz dünyada kiraz üretiminde ve ihracatında önemli yere sahiptir.

Anadolu coğrafyasında bahçe kültürü içerisinde önemli olan bir meyve olan kirazda (Purunus avium L.) en eski kültür alanlarından biridir (Ülkümen, 1973). Kirazın anayurdu Hazar Denizi, Güney Kafkasya ve Kuzeydoğu Anadolu arasındaki bölge olduğu ve bu gen merkezlerinden doğuya ve batıya dünya üzerinde geniş bir alana yayılmıştır (Özbek, 1978).

Dünyada kiraz üretiminde ve ihracatında önemli yere sahip olan Türkiye'nin, kiraz ihracatı 1985 yılından sonra başlamıştır. 2018 yılında 639.564 ton kiraz üretimiyle dünya birincisidir. Ülkemiz, 2018 yılında miktar olarak yaklaşık 70 bin ton, değer olarak ise 162 milyon dolarlık ihracat gerçekleştirmiştir. Ülkemiz Kiraz diş satımında Avrupa Birliği ülkeleri önemli yer tutmakta olup, 15 'in üzerinde ülkeye kiraz ihraç edilmektedir (Anonim, 2018). Diyarbakır ilinde 2018 yılında 353 ton, kiraz üretimi yapılmıştır (Anonim, 2019).Bölgede kiraz üretim miktarı nispeten düşük gibi görünse de bölgede yetiştiriciliği yapılan kirazın erkenci olması ve dolayısı ile ekonomik getirisinin yüksek olması kirazı bölge için önemli kılmaktadır.

Ülkemizde Kirazda zararlı olan zararlı böcekler ve doğal düşmanları üzerine Aysu,1955; Nizamoğlu, 1957; Gökmen, 1965; Yıldırım, 1957; Ulu,1983; Doğanlar, 1987; Ulu ve Önuçar, I989, Uzun,1990; Özbek ve ark.,1996; Erol ve Yaşar, 1996. Özder, 1999; Çınar ve ark., 2004, Ertop ve Özpınar, 2011; Özdem ve ark., 2017; Kaplan ve Alaserhat, 2018, Kaplan, 2019 gibi bir çok sayıda araştırıcı çalışma yürütmüş ve kirazda 70' in üzerinde zararlı böcek bildirmişlerdir. Bunlardan bazıları (Arcips rosanus, L. Capnodis sp., Scolytus rugulosus Müller ve Tetranychus urticae Koch) çiçek ve tomurcuklarda bazıları da yapraklarda hem beslenmesi hem de bükmesi ve ağacın kök, gövde dalların içinde beslenerek önemli zararlara neden olduklarını kaydetmişlerdir.

Çalışmanın yürütüldüğü Diyarbakır ilinde kiraz bahçelerinde üretimi sınırlayan önemli etkenlerden birisi bitki koruma sorunlarıdır. Nitekim yapılan araştırmalar ve bölge illerindeki ilgili tarım kuruluşlardan ve üreticilerden edinilen bilgiler sonucu, kiraz zararlılarının bölgede önemli oranda zarara sebep olduğu ve bu nedenle pesitisit kullanımının giderek arttığı gözlenmiştir. Bu zararlı böcek ve akar türleri (Capnodis sp., Archips sp., ve T. urticae ) bölgede kiraz bahçelerinde ekonomik yönden önemli oranda zarara neden olduğu gözlemlenmiştir. Son zamanlarda bölgede meyve bahçelerinde zararlı organizma türleri ile mücadelede gelişi güzel pestisit kullanımının artmasıyla canlılar var olan doğal dengenin bozulmasına neden olacak ki, buda ileriki yıllarda zararlıların salgın yapma ihtimalini arttıracaktır. Mevcut olan bu olumsuz iyileştirilmesi hem çevre ve insan sağlığı hem de kaliteli ürünün piyasaya sunulması açısından önemlidir. Bu nedenle sürdürülebilir tarımsal üretim ve kalkınmayı sağlamak için entegre mücadele sisteminin uygulanması gerekir.

Kiraz bahçelerinde yapılan bu çalışmada zararlı türleri ile etkili bir mücadele yapmak için de öncelikle türlerin belirlenmesi, doğada görülme zamanı ve zarar şekli ortaya konulmuştur. Çalışma sonucunda kiraz ağaçlarında tespit edilen zararlı türlerin ve önemli türlerin doğada görülme zamanın belirlenmesiyle gerek bölgede gerekse de ülkemizde kiraz üretimi ile uğraşan üreticiler ve teknik elemanlar için zararlı ile mücadelede temel veriler elde edilmiştir.

\section{Materyal ve Metot}

\subsection{Materyal}

Çalıșmanın ana materyalini Diyarbakır (GAP ULUSLARARASI TARIMSAL ARAŞTIRMA VE EĞİTIM MERKEZİ ve ZİRAİ MÜCADELE ARAŞTIRMA ENSTITTÜSÜ deneme bahçesi) ili kiraz bahçeleri ile buralardan toplanan Tortricidae familyasına ait böcek türlerin yumurta, larva, pupa ve erginlerine ait örnekler, bunların parazitoit ve predatörleri, çukur tuzak, eşeysel çekici tuzaklar, şaraplı besi tuzağı ile çeşitli laboratuvar malzemeleri oluşturmuştur. Kiraz sineği (Rhagoletis cerasi L.) için $15 \times 20 \mathrm{~cm}$ boyutlarında Rebell sarı renkli görsel yapışkan tuzak + Amonyak tablet kullanılmıştır (Özdem, 2001). Yaprakbükenler ve diğer bazı türlerin erginlerini yakalamak için besin tuzakları (100 ml şarap, $900 \mathrm{ml}$ su, 25 gr seker ve 25 ml sirke) kullanılmıştır. (Tezcan ve Okyar, 2004).

\subsection{Metot}

\subsubsection{Doğa Çalıșmaları}

Diyarbakır (GAP ULUSLARARASI TARIMSAL ARAŞTIRMA VE EĞİTİM MERKEZİ ve ZİRAİ MÜCADELE ARAŞTIRMA ENSTİTÜSÜ deneme bahçesi) kiraz bahçelerinde zararlı ve faydalı türler ile önemli türlerin doğada görülme zamanını belirlemek için Mart ayından itibaren sürvey yapılmıştır. Kiraz bahçelerinde 2015-2016 yılları arasında vejetasyon süresi boyunca haftada bir kez diğer dönemlerde ise iki haftada bir kez örnekler düzenli aralıklarla alınmıştır. Örneklemelerde bahçelerin ilaçlanmamış ve bakımsız olmasına özen gösterilmiş ve her bahçede incelenen ağaç sayısı Grigorov (1974)'a göre belirlenmiştir (Çizelge 1). Kiraz sineğinin (Rhagoletis cerasi L.) takibinde $15 \times 20 \mathrm{~cm}$ boyutlarında Rebell sarı renkli görsel yapışkan tuzak + Amonyak tablet kullanılmıştır (Özdem, 2001). Yaprakbükenler ve diğer bazı türlerin erginlerini yakalamak için besin tuzakları (100 $\mathrm{ml}$ şarap, $900 \mathrm{ml} \mathrm{su}, 25$ gr seker ve $25 \mathrm{ml}$ sirke) kullanılmıştır (Tezcan ve Okyar, 2004).

Çizelge 1. Çalışmaların yapıldığg Bahçelerde gözlemlenen ağaç miktarı (Grigor, 1974) 


\begin{tabular}{c|c}
\hline $\begin{array}{l}\text { Bahçedeki Mevcut Ağaç Miktarı } \\
\text { (adet) }\end{array}$ & Gözlemlenmesi Gereken Ağaç Miktarı (adet) \\
\hline $1-20$ & Tamamı \\
$21-70$ & $21-30$ \\
$71-150$ & $31-40$ \\
$151-300$ & $41-80$ \\
$301-1000$ & $\% 15$ \\
\hline
\end{tabular}

\subsubsection{Laboratuvar Çalışmaları}

Bahçelerden toplanan böcekler ve akar türleri laboratuvarda önce birbirlerine benzerliklerine göre gruplandırılarak numaralandırılmıştır. Bununla birlikte yaprakbitleri (afit) gibi yumuşak vücutlu olan bireyler \% 70'lik alkol içine alınmıştır. Ergin öncesi dönemde bulunan bireyler ise bulunduklar bitki kısmıyla beraber iklimlendirme odasında ayrı ayrı kültür kafeslerine alınarak ergin elde edilmeye çalıșılmıștır. Daha sonra böcekler takım, familya ve türlerine göre iğnelenip, etiketlenerek uygun kutulara alınarak tanı için konu uzmanına gönderilmiştir.

\section{Araştırma Sonuçları ve Tartışma}

\subsection{Zararlı türler}

Çalışma sonuçlarına göre örnekleme bahçelerinde fitofag türlerden 28 böcek ve 1 akar ile genel predatör ve parazitoitlerden olan 14 faydalı böcek türü saptanmıştır. Saptanan zararlı türlerden Archips rosanus L., Tropinota hirta Poda, Stephanitis pyri Fabricius, Myzus cerasi F., Capnodis tenebrionis L., Scolytus rugulosus Müller ve Tetranychus urticae Koch.'un ekonomik yönden zararlı olduğu gözlenmiştir.

Çizelge 2. Diyarbakır ili kiraz ağaçlarında 2014-2015 yıllarında belirlenen zararlı böcek ve akar türleri

\begin{tabular}{|c|c|c|}
\hline Takım & Familya & Tür \\
\hline \multirow[t]{8}{*}{ Coleoptera } & Buprestidae & Capnodis tenebrionis (Linnaeus) \\
\hline & & Capnodis carbonaria (Klug) \\
\hline & Cantharidae & Cantharis decipiens (Baudi) \\
\hline & Curculionidae & Polydrusus ponticus (Faust) \\
\hline & & Lixus cardui (Oliver) \\
\hline & & Hypera variabilis (Herbst) \\
\hline & Scarabaeidae & Tropinota $(=$ Epicometis) hirta $($ Poda $)$ \\
\hline & Scolytidae & Scolytus rugulosus (Müller) \\
\hline Diptera & Tephritidae & Rhagoletis cerasi (L.) \\
\hline \multirow[t]{5}{*}{ Hemiptera } & Aphididae & Myzus cerasi (Fabricius) \\
\hline & Cicadellidae & Empoasca decipiens (Pao) \\
\hline & Issidae & Agalmatium flavescens Oliv \\
\hline & Pentatomidae & Eurydema ornata $(\mathrm{L})$. \\
\hline & Tingidae & Stephanitis pyri (Fabricius) \\
\hline Hymenoptera & Tenthredinidae & Caliroa limacina (Retzius) \\
\hline \multirow[t]{13}{*}{ Lepidoptera } & Tortricidae & Archips rosanus (L.) \\
\hline & & Aphelia ferugana (Hübner) \\
\hline & & Aphelia viburnana (Den.\& Sch.) \\
\hline & & Cnephasia tianshanica (Filipjev) \\
\hline & & Cydia pomonella $(\mathrm{L})$. \\
\hline & & Hedya nubiferana (Haw) \\
\hline & & Lobesia botrana (Den.\& Schif.) \\
\hline & & Tortrix viridana (L.) \\
\hline & Arctiidae & Arctia villica (L.) \\
\hline & Lymantridae & Lymantria dispar (L.) \\
\hline & Pieridae & Aporia crataegi (L.) \\
\hline & Noctuidae & Acronicta psi (L.) \\
\hline & & Noctua fimbriata (Schreber) \\
\hline Acarina & Tetranychidae & Tetranychus urticae (Koch.) \\
\hline
\end{tabular}

Ülkemiz kiraz alanlarında yapılan çeşitli çalışmalarda; Özder (1999); Tekirdağ ili ve çevresindeki kiraz bahçelerinde 23 zararlı böcek türü tespit etmiş ve bunlardan 5 türün yaygın olduğunu bildirmiştir. Ulusoy ve ark. 1999, Pozantı ve Ulukışla kiraz bahçelerinde toplam 86 zararlı böcek türü belirlemiş ve bunlardan bazılarının ekonomik olarak önemli olduğunu bildirmektedirler. Benzer başka bir çalışmada Çınar ve ark. 2004, Elazı̆̆ ve Mardin illeri kiraz alanlarında yaptıkları çalışma sonucunda 36 zararlı tür 
belirlediklerini bildirmişlerdir. Ertop ve Özpınar (2011), Çanakkale ili kiraz bahçelerinde 2005-2006 yıllarında yürütülen bir çalışmada 9 takımda 32 familyaya ait 51 böcek ve 4 akar türü belirlediklerini ve bu türlerden C. tenebrionis, T. hirta, L. dispar, S. rugulosus, $M$. cerasi, A. rosana, $R$. cerasi ve C.molesta'nın kiraz ağaçlarında önemli zarara neden oldukları gözlemlediklerini bildirmektedirler.

\subsection{Faydalı türler}

Kiraz bahçelerindeki zararlı organizmaların doğal düşman türlerini belirlemek amacıyla örneklemeler yapılmıştır. Bu amaçla kiraz bahçelerinden toplanan ve laboratuvarda kültüre alınan zararlı ile bulaşık bitki örneklerinde parazitoit ve predatörleri saptanmaya çalışılmıştır. Kiraz bahçelerinde ağaç dallarına yapılan darbe yöntemi yanı sıra besi tuzaklarından elde edilen genel predatör ve parazitoitlerden olan 5 takıma bağlı 6 familya ait 14 faydalı böcek türü saptanmıştır (Çizelge 3).

Çizelge 3. Mardin ve Elazı ̆ illerinde 2015-2016 yıllarında kiraz bahçelerinde belirlenen genel predatör ve parazitoit türleri

\begin{tabular}{|c|c|c|}
\hline Takım & Familya & Tür \\
\hline Coleoptera & Coccinellidae & $\begin{array}{l}\text { Adalia fasciatopunctata (Mulsant) } \\
\text { Coccinella semtempunctata (L.) } \\
\text { Coccinella undecimpunctata (L.) } \\
\text { Chilocorus bipustulatus (L.) } \\
\text { Oenopia (Synharmonia) conglobata (L.) } \\
\text { Scymnus pallipediformis (Günther), } \\
\text { Stethorus punctillum (Weise) } \\
\text { Psyllobora vigintiduopunctata (L.) }\end{array}$ \\
\hline Dermaptera & Forficulidae & Forficula auricularia L. \\
\hline Diptera & Syrphidae & $\begin{array}{l}\text { Episyrphus balteatus De Geer } \\
\text { Metasyrphus corollae Fabricius }\end{array}$ \\
\hline Hemiptera & $\begin{array}{l}\text { Reduvidae } \\
\text { Nabidae }\end{array}$ & $\begin{array}{l}\text { Nagusta goedeli Kaltenbach } \\
\text { Nabis punctatus (Costa) }\end{array}$ \\
\hline Hymenoptera & Braconidae & Apantales sp. \\
\hline
\end{tabular}

Özder (1999), Tekirdağ ili kiraz bahçelerinde 12 predatör ve 17 parazitoit ile birlikte toplam 29 faydalı böcek bulduklarını bildirmişlerdir. Ertop ve Özpınar (2011), Çanakkale ili kiraz bahçelerinde 13'ü predatör, 6'sı ise parazitoit tür olmak üzere 19 yararlı böcek türü belirlediklerin bildirmişlerdir.

Çalışmalarda zararlının değişik dönemleriyle bulaşık bitki örneklerinden Archips türlerinin bilinen parazitoitlerden Apanteles sp. (Hym.:Braconidae) türü elde edilmiştir. Nitekim Aydoğdu ve ark. (2011) tarafindan Edirne ilindeki organik kiraz bahçelerinde de çalışmamızda belirlediğimiz türlerden benzer türleri tespit etmişlerdir. Bu türler Pimpla spuria Gravenhorst, Scambus buolianae (Hartig), Bracon (Habrobracon) hebetor Say, B. (Bracon) intercessor Nees, Meteorus versicolor (Wesmael) ve M. rufus (DeGeer) gibi faydalı türleri’nin A. rosana'yı parazitlediğini tespit etmişlerdir. Özdemir ve Özdemir (2002), Orta Anadolu Bölgesinde19842001 yılları arasında Archips spp. türlerinde (Lep.:Tortricidae) saptanan Ichneumonidae (Hym.) familyasına ait türler ile ilgili yaptıkları çalışmada toplam 14 tür parazitoit türü saptamışlardır. Piekarska-Boniecka ve ark., (2008), tarafından 2004 ve 2007 yıllarında Polonya'nın elma bahçelerinde A. rosana'nın parazitoit tür kompozisyonu ve parazitlenmesi üzerine yaptıkları çalışmada $A$. rosana pupasının Ichneumonidae, Chalcidoidea (Hymenoptera) ve Tachinidae (Diptera) gruplarının parazitoitleri ile parazitlendiğini belirlemişlerdir. Polat ve Tozlu (2010), Erzurum Atatürk Üniversitesi Kampüsü'ndeki kiraz alanlarında 2004-2005 yıllarında yürüttükleri çalışmada, Archips rosana (Linnaeus, 1758) (Lep.: Tortricidae)'nın parazitoitlerini belirlemişlerdir. Zararlının Hymenoptera takımına ait Ichneumonidae'den 4, Pteromalidae'den 2, Chalcididae'den 1, Torymidae'den 2, Eulophidae'den 1 ve Eupelmidae'den de 1 olmak üzere, toplam 11 parazitoit türünü tespit etmişlerdir. Bu türler içerisinde elde edilen tüm parazitoit türlerinin popülasyonunun \% 41.48'ini oluşturan Itoplectis maculator' nın (Fabricius, 1775) (Hymenoptera: Ichneumonidae) en önemli parazitoit türü olduğunu tespit etmişlerdir.

Çalışmanın yürütüldüğü kiraz bahçelerinde bulunan ve genel predatörlerden biri olan Coccinellidae familyasına ait 8 tür tespit edilmiştir. Bu türlerden Coccinella semtempunctata (L.), Scymnus pallipediformis (Günther), ve Stethorus punctillum (Weise) türleri Diyarbakır ilindeki kiraz alanlarında yoğun olarak bulunmuştur. Çalışmanın yapıldığı kiraz bahçelerinde Syrphidae familyasına bağlı Metasyrphus corollae (F.) ve Episyrphus balteatus (De Geer) türleri belirlenmiştir. Sürvey yapılan kiraz alanlarında yoğun şekilde Chrysopidae familyasına ait Chrysoperla carnea'nın ergin ve larvaları saptanmıştır.

Kaplan ve Yücel, 2014. Çilek alanlarında; Kaplan ve Bayhan, 2014. Bağ alanlarında; Kaplan ve ark., 2016. Zeytin bahçelerinde. zararlı böcek türleri bir arada bulunan predatörlerden Coccinellidae familyasından Coccinella semtempunctata L., C. undecimpunctata L., Chilocorus bipustulatus L., Stethorus sp., Scymnus sp., Hippodamia variegata Goeze ve Synharmonia conglobata L., Chrysopidae familyasından Chrysoperla carnea Stephens, Nabidae familyasından Nabis punctatus Costa, Reduvidae familyasından Nagusta goedeli Kolenatil, Syrphidae familyasından Metasyrphus corollae Fabricius, Eristalis arbustorum L. ve Episyrphus balteatus De Geer'i tespit ettiklerini ve bu türlerin söz konusu bitkisel üretim alanlarında yaygınlık ile yoğunluk açısından önemli bulduklarını bildirmişlerdir. Kütük ve Güçlü (2016), Erzincan ilinde yetiştirilen kirazlarda yaprakbiti türlerinin avcısı olan 8 predatör tür tespit ettiklerini bildirmişlerdir. 
Çeşitli zamanlarda yapılan araştırmalarda Cranshaw (2004), C. carnea erginlerinin nektar ve polen ile beslenmeleri yanı sıra $C$. carnea larvalarının ise thrips, yaprakbiti ve küçük tırtılların predatörü olduğu bildirmiştir. Öncüer (1991), C. carnea 'nın yaprakbitleri üzerinde ciddi etkileri olduğunu ortaya açıklamıştır. Ayrıca yapılan başka bir çalışmada (Kaya ve Öncüer 1988, Yoldaş 1994) $C$. carnea'nın polifag bir tür olduğu, larvalarının thripsler, yaprakbitleri, bazı kabuklubitler, lepidopter yumurta ve larvaları, pysillidler, Chrysomelidae familyasına bağlı larvalar, bazı akar türleri ve beyazsinekler ile beslendiği bildirmişlerdir.

\subsection{Bazı önemli zararlı türlerin doğada görülme zamanı}

Çalışma yapılan kiraz bahçelerinde 28 zararlı türden en yoğun olarak lepidoptera takımından Tortricidae familyasına ait Archips rosanus (L.) başta olmak üzere 8 adet Archips türü belirlenmiştir. Söz konusu türlerden $A$. rosanus 'un larvaları Diyarbakır İlinde mart ayının ikinci yarısından sonra kiraz yapraklarında görülürken erginleri ise Mayıs ayının ikinci haftasında itibaren tuzaklarda görülmüş ve son olarak tuzaklarda Haziran ayının son haftasında görülmüştür. Söz konusu zararlının larvaları ilk iki evresinde yeni sürmüş yaprakların uçkısmını,; gözlerin iç, dış ve dip kısımlarından, sonra ağacın tomurcukları çiçeklerinde beslenmektedir. Ayrıca meyveleri kemirerek ürün kaybına ve kalite düşüklüğüne neden olur. Özder (1999), Tekirdağ ili ve çevresi kiraz ağaçlarında yürüttükleri bir çalışma sonucunda elde edilen 23 zararlı türden en yoğun olarak Archips türlerin olduğunu bildirmiştir. Çınar ve ark. (2004), A. rosanus'un larvaları Mardin İli Kiraz ağaçlarındaki yapraklarda şubat sonunda, Elazı̆̆ İlinde mart ayının ilk yarısında kiraz yapraklarında görüldügünü, zararlının larvasının birinci ve ikinci döneminde ağacın çiçek ve tomurcuklarında beslenmesi yan sıra yeni sürmüş yaprakları bükerek 2-10 adet yaprağı ipeksi ağlarla birbirine bağlayıp buket haline getirdiğini bildirmektedirler. Kaplan ve Alaserhat (2019), Mardin ve Elazığ ileri kiraz bahçelerinde 2017 yılında yürüttükleri çalışmada, A. rosanus erginlerinin Mayıs ayının üçüncü haftası ile Temmuz ayının son haftası arasında tuzaklarda görüldüğü ve dolaysıyla uçuş periyodunun 64-71 gün sürdüğünü bildirmiştir. Archips türleri, karakteristik olarak genç yaprakları bükerek 3-6 adet yaprağı ipeksi ağlarla birbirine bağlayıp buket haline, tek yaprağı ise orta damar doğrultusunda puro gibi uzunlamasına sarmaktadır. Bu zararlı türün populasyon yoğunluğunun yüksek olduğu bahçelerde önlem alınmadı̆̆ı durumda ileri ki dönemlerde tüm yapraklara zarar vererek meyve ağaçlarında verim ve kalite kaybına neden olduğu belirlenmiştir.

Kiraz bahçelerinde ana zararlı durumunda olan Rhagoletis cerasi L. (Kiraz sineği) ise çalışma yapılan bahçelerinde düşük yoğunlukta bulunmuştur. Erginler mayıs ayı başlarından itibaren tuzaklarda görülmüş, uçuşu başladıktan 2-3 hafta sonra tuzaklarda yakalanan ergin sayısı bir tepe noktası oluşturmuş ve bahçelere her iki yılda da uçuş periyodu 30-45 gün arasında sürmüştür. Nitekim Kaplan (2019), Elazı̆g ili kiraz bahçelerde eşeysel çekici tuzaklarda Kiraz sineğinin ilk erginleri mayıs ayının ilk haftasında görüldüğünü, popülasyon gelişiminin yaklaşık 21-42 gün arasında devam ettiğini bildirmiştir. Ekolojik koşullar, rakım, yöney ve bitkinin vejetasyon süresi; erginin doğaya çıkış tarihini, popülasyon gelişimini ve bitişini etkilediğini, bununla birlikte yıllara göre kiraz bahçelerinde hasat zamanı kontrol edilen 1000 adet meyvede \%0.2 ve \%0.4 arasında bulaşma (Kurtlu meyve) saptadığını bildirmiştir (Kaplan, 2019). Borovinova ve Sredkov (2006), Bulgaristan'da, Entegre ve geleneksel yöntemlerle kiraz üretimini karşılaştırdıkları çalışmalarında, ana zararlı olarak Rhagoletis cerasi'yi belirlemişlerdir.

S. pyri'nin nimf ve erginleri çalışmanın yapıldığı illerin kiraz üretilen alanlarında mayıs ve eylül ayların kiraz yapraklarında beslemesi sonucu ağaçların sağlıklı bir şekilde fotosentezi yapmaması sonucu verim ve kalite kaybına neden olmaktadır. Nitekim Çam (1993), S. pyri'nin Tokat İlinin Kiraz bahçelerinde yaygın olduğunu, nimf ve erginlerin kiraz, vişne ve idris ağaçlarında yaprakların alt yüzeyini sokup emerek beslenmesi sonucu zarar oluşturduğunu belirtmiştir. Yine, Önder et al. (1995), Güneydoğu Anadolu Bölgesi'nde sulu tarıma geçilmesi halinde bölgede henüz fazla zararı görülmeyen S. pyri 'nin zararının artacağını bildirmişlerdir.

Çınar ve ark. (2004), S. pyri’nin çalışmanın yürütüldüğü illerin kiraz yetiştirilen alanlarda nisan- eylül ayları arasında aktif olduğunu saptanmıştır.

M. cerasi çalışmanın yapıldığı bahçelerde yaygın olup nisan-eylül ayları arasında görülmüştür. Yağışlı ve sıcak geçen Nisan ve Mayıs aylarında zararlı kirazın yeni yaprak ve genç sürgünlerde kümeler oluşturarak, yaprakların bükülmesi ve bol miktarda fumajine neden olmaktadır. Çınar ve ark. (2004), tarafında yapılan bir çalışmada M. cerasi'nin nisan-eylül ayları arasında kiraz bahçelerinde görüldüğünü ve zarar yaptığını bildirmiştir.

Kiraz bahçelerinde çiçeklenmenin başlamasıyla T. hirta'nın erginleri iklim koşullarına bağlı olarak nisan ayını ilk haftasında itibaren tuzaklarda görülmekte nisanın ortalarına doğru ergin sayısı en yoğun düzeye ve son olarak mayıs ayının ilk haftasına kadar tuzaklarda görülmüştür. Bu zararlı doğrudan çiçeklerde beslenerek zarar oluşturmaktadır. Çınar ve ark., (2004) T. hirta'nın kirazlarla beslendiğini, Ulusoy ve ark. (1999) bu türün kirazlar için ekonomik olduğunu bildirmiştir.

$\mathrm{Bu}$ çalışma kiraz bahçelerinde İki noktalı kırmızı örümcek (Tetranychus urticae) erginleri iklim koşullarına bağlı olarak nisan ayının ikinci veya üçüncü haftasında yapraklarda ilk olarak görülmüş ve önemli bir zararlı olarak belirlenmiştir. Kaplan ve Yücel (2014), Elazı̆̆ ili çilek alanlarında kırmız örümceklerin yaygınlık ve yoğunluk açısından önemli bir zararlı olduğunu bildirmişlerdir. Kırmızı örümcekler kiraz ağaçlarının yapraklarında, bitki özsuyunu emmesi ve zehirli madde salgılamasıyla yarak zarar oluştururlar. Bunun sonucunda ağacın yapraklar önce beyaz, sonra sarı ve kahverengi lekeler oluşur.Bu lekeler birleşerek yaprağın kuruyup dökülmesi sonucu meyveler güneş yanıklığına maruz kalması yanı sıra ürün kaybına neden olur.

\section{Sonuç}

Diyarbakır ili kiraz ağaçlarında fitofag ve faydalı türler ile önemli bazı türlerin doğada görülme zamanı belirlemek amacıyla yürütülmüştür. Yürütülen bu çalışma sonucunda kiraz bahçelerinde fitofag türlerden 28 böcek ve 1 akar ile genel predatör ve parazitoitlerden olan 14 faydalı böcek türü saptanmıştır. Saptanan zararlı türlerden A.rosanus, R. cerasi, Tropinota hirta Poda, Stephanitis pyri Fabricius, M. cerasi, C. tenebrionis, S. rugulosus ve T. urticae'in ekonomik açıdan zararlı olduğu gözlenmiştir. Ayrıca C. semptempunctata, Synharmonia conglobata L., Scymnus pallipediformis Gunther, M. corollae ve C. carnea'nın Diyarbakır ili e-ISSN: 2148-2683 
Kiraz ağaçlarında en fazla görülen yararlı türler olduğu belirlenmiştir. Kiraz bahçelerinde saptanan zararlı türden en yoğun olarak lepidoptera takımından Tortricidae familyasına ait $A$. rosanus başta olmak üzere 8 adet Archips türü belirlenmiştir. Söz konusu türlerden A. rosanus 'un larvaları Diyarbakır İlinde nisan ayının ikinci yarısından sonra kiraz yapraklarında görülmektedir. Kiraz bahçelerinde ana zararlı durumunda olan kiraz sineği ise çalışma yapılan bahçelerinde düşük yoğunlukta bulunmuştur. Erginler mayıs ayı başlarından itibaren tuzaklarda görülmüş ve her iki yılda da bahçelerde uçuş periyodu 30-45 gün arasında sürmüştür. $S$. pyri’nin nimf ve erginleri çalışmanın yapıldığı illerin kiraz üretilen bahçelerinde mayıs ve eylül ayları arasında kiraz yapraklarında beslemesi sonucu ağaçların sağlıklı bir şekilde fotosentezi yapmaması sonucu verim ve kalite kaybına neden olmaktadır. M. cerasi çalışmanın yapıldığı bahçelerde yaygın olup nisan-eylül ayları arasında görülmüştür.

Günümüzde insan sağlığının, çevrenin ve biyolojik çeşitliliğin korunması ön plandadır. Modern bir yaklaşımla, zararlı türlerle mücadele ederken tüm faktörlerin çevresiyle birlikte düşünülmesi gerekir. Kirazlarda zararlılarla birlikte faydalı türlerinin de yaygın olduğu alanlarda uygulanacak mücadele yöntemlerinde, geniş spektrumlu kimyasal ilaç ve gereksiz ilaçlamalardan kaçınılması önerilir. Çünkü biyolojik mücadele kapsamında yararlı türler korunduğu ve etkinlikleri artırıldığı sürece entegre mücadele açısından önemli adımlar atılmış olacaktır. Neticede "Entegre mücadele" programlarının ilk basamağı mevcut faunanın belirlenmesidir, diğer çalışmalar ancak bu aşamadan sonra yapılabilmektedir.

Sonuç olarak kiraz bahçelerindeki zararlı türler kiraz ağaçlarının sürgün, yaprak, tomurcuk, çiçek ve meyvelerinde beslenerek verim ve kaliteyi düşürmektedir. Meyve bahçelerinde zararlı organizma türleri ile mücadelede gelişi güzel pestisit kullanımının artmasıyla canlılar var olan doğal dengenin bozulmasına neden olacak ki, buda ileriki yıllarda zararlıların salgın yapma ihtimalini arttıracaktır. Nitekim kiraz bahçelerinde belirlenen zararlı türler ile mücadelede başarılı olmak için öncelikle doğada faydalı türlerin belirlenmesi, korunması ve etkinliklerinin artırılması amacıyla ilaçlama zamanı, ve sayısı yönünde elde edilmiş olan bilgiler kiraz üreticisi ile paylaşılacaktır. Böylece gereksiz ilaçlamaların önüne geçilerek üründe kalite ve verim kaybı yanı sıra üründe kalıntı nedeniyle tüketimde ve ihracatta sorun yaşanmayacak ve sağlıklı bir şekilde bu ürün tüketilebilecektir.

\section{Teşekkür}

Çalışmalarımda elde etmiş olduğum, Coccinellidae teşhisleri Prof. Dr. Nedim UYGUN (Çukurova Üniversitesi, Ziraat Fakültesi, Bitki Koruma Bölümü, Adana), Syrphidae teşhisleri Prof. Dr. Ahmet Faruk ÖZGÜR (Çukurova Üniversitesi Ziraat Fakültesi, Bitki Koruma Bölümü, Adana), Chrysopidae teşhisleri Doç. Dr. Ali SATAR (Dicle Üniversitesi Fen Fakültesi, Biyoloji Bölümü, Diyarbakır), Nabidae ve Reduvidae teşhisleri Doç. Dr. Ahmet DURSUN (Amasya Üniversitesi, Fen Fakültesi, Biyoloji Bölümü, Amasya), Lepidoptera türlerini Dr. Mustafa ÖZDEMIR (Ankara Zirai Mücadele Merkez Araştırma Enstitüsü, Dermaptera türlerinin teşhisi Prof. Dr. Ali DEMIRSOY (Hacettepe Üniversitesi) ve Braconidae teşhisleri Prof. Dr. Ahmet BEYARSLAN (Bitlis Eren Üniversitesi, Üniversitesi, Fen Fakültesi, Biyoloji Bölümü, Bitlis) tarafından yapılmış olup, tüm hocalarıma teşekkürlerimi sunarım.

\section{Kaynakça}

Anonymous, (2016). (http://faostat3.fao.org/faostat-gateway/go/to/download/Q/QC/E).

Anonim, (2018). (www.tüik.gov.tr) (Erişim Tarihi: 17.03.2019)

Aydoğdu, M., Beyarslan, A. \& Yılmaz, T., (2011). Organik Kiraz Bahçelerinde Archips rosana (Linnaeus, 1758) (Lepidoptera: Tortricidae) Üzerinde Gelişen Parazitik Arılar. Türkiye IV. Bitki Koruma Kongresi Bildirileri, Kahramanmaraş.

AYSU, R., (1955). Yaprak büken "Cocoecia". Bornova Zir. Müe. Ens!. Yay. No.39.

Borovinova, M. \& Sredkov, I., 2006. Comparison of Integrated and Conventional Plant Protection Of Cherry Orchards. Not. Bot. Hort. Agrobot. Cluj, XXXIV

Cranshaw, W., (2004). Biological Controls IX. Insect Predators. http://highplainsippm.org

Çınar, M., Çimen, İ. \& Bolu, H., (2004). Elazığ ve Mardin illeri kiraz ağaçlarında zararlı olan türler, doğal düşmanları ve önemlileri üzerinde gözlemler. Türkiye Entomoloji Dergisi, 28 (3): 213-220

Düzgüneş, Z., (1980). Küçük Arthropodların Toplanması, Saklanması ve Mikroskopik Prepatlarının Hazırlanması. Gıda Tarım Hayvancılık Bakanlığg Zirai Mücadele Zirai Kar. Gn. Müdürlüğü Yayınları. Ankara, 778 s.

Erol, T. \& Yaşar, B., 1996. Van ili elma bahçelerinde bulunan zararlı türler ile doğal düşmanları. Türkiye Entomoloji Dergisi, 20(4)281-293.

Ertop, S. \& Özpınar, A., (2011), Çanakkale İli kiraz ağaçlarındaki fitofag ve yararlı türler ile bazı önemli zararlıların popülasyon değişimi. . Türkiye Entomoloji Dergisi, 1(2):109-118.

Gökmen, N., (1965). Kirazlarda Yaprak BUken (Cacoecia spp.) ve Mücadelesi. Tar. Bak. Zir. Müc. Zir. Kar. Gn. Md. Mes. Neş. Ser. Ç.B.No:3, $12 \mathrm{~s}$.

Grigorov, S.P., (1974). Karantina na Restaniata. Zemizdat, Sofya, 346 pp.

Kaplan, M. \& Yücel, A., (2014). Elazı̆̆ İli Çilek Alanlarında Belirlenen Zararlı Böcek ve Akar Türleri, Meyve Bilimi Dergisi ISSN: 2148-0036 Cilt (Say1) /Vol.(Issue): 1(2) Sayfa/Page: 7-14, Isparta.

Kaplan, M. \& Bayhan, E., (2014). Mardin İli Bă̆ Alanlarında Thripslerle Birlikte bulunan Doğal Düşmanlar . Uluslararası Mezopotamya Tarım Kongresi (IMAC 2014), 176 s. (22-25 Eylül 2014), Diyarbakır.

Kaplan, M., Özgen, İ. \& Ayaz, T., (2016). Mardin İli Zeytin Bahçelerinde Zeytin Pamuklubiti [Euphyllura straminea Loginova (Hemiptera: Psyllidae)]'nin Doğal Düşmanları ve Önemli Türlerin Popülasyon Değişimi. Harran Tarım ve Gıda Bilimleri Dergisi Cilt 20, Say1 3 (2016), 175-182s.

Kaplan, M., (2019). Elazı̆̆ İli Kiraz Üretim Alanlarında Kiraz Sineği (Rhagoletis Cerasi L.) (Diptera:Tephritidae)'nin Doğaya Çıkış Zamanı, Populasyon Değişimi ve Bula-şıklık Oranını Belirlenmesi. Avrupa Bilim ve Teknoloji Dergisi Sayı 16, S.363-366. 
Kaplan, M. \& Alaserhat, İ., (2018). Phytophagous and Beneficial Species on Cherry Trees and Time to Being Seen of Some Important Species in Nature in Mardin and Elazig Provinces Turkey. IV. International Congress on Mathematİcs, Engineering \& Natural \& Health Sciences İn Kiev, Ukraine On August 11-14, 2018.

Kaplan M. \& Alaserhat, İ., (2019). Investigation, on Mass-Trapping of Arcips rosanus L. (Lepidoptera: Tortricidae), pest of Cherry Trees. Fresenius Enviromental Bulletin, Volume 8-No. 2A/2019 pages: 1308-1311.

Kaya, Ü. \& Öncüer, C., (1988). Laboratuvarda Üretilen Chrysoperla carnea (Steph.) (Neuroptera: Chrysopidae)'nın Biyolojisine Farklı İki Besinin Etkisi Üzerinde Bir Araştırma. Türkiye Entomoloji Dergisi, 12 (3): 151-159.

Kütük, Y. \& Güçlü, Ş., (2016). Erzincan ilinde kirazlarda (Prunus avium L.) zarar yapan Aphididae (Hemiptera) türleri ile parazitoit ve predatörlerinin belirlenmesi. Bitki Koruma Bülteni 2016, 56(2): 155 - 163.

Nizamoğlu , K., (1957). Türkiye Meyve Ağaçları Zararlıları ve Mücadelesi. Koruma Tarım ilaçlan A.Ş. No:5, 508s.

Öncüer, F., (1991). Türkiye Bitki Zararlısı Böceklerin Parazit ve Predatör Kataloğu. Ege Üniversitesi Ziraat Fakültesi Yayınları No: 505, İzmir, 281s.

Özbek, S., (1978), Özel Meyvecilik. Çukurova Üniversitesi Ziraat Fakültesi Yayınları, No: 128, Adana

Özbek, H., GÜÇLÜ, Ş. \& Hayat, R., (1996). Kuzeydoğu Tarım Bölgesinde taş çekirdekli meyve ağaçlarında bulunan fitofag ve predatör böcek türleri. Türk Tanm ve Ormancılık Dergisi 20,267-282.

Özdem, A., (2001). Orta Anadolu Bölgesinde Kiraz Sinegi [(Rhagoletis cerasi L.) (Diptera: Tephritidae)]'nin Biyolojisi ve Biyoteknik Savasım Yöntemleri Üzerinde Arastırmalar. Doktora Tezi, Fen Bilimleri Enstitüsü, S. 114, Ankara

Özdem, A., Bozkurt, V., Güler, Y. \& Özdemir, M., (2017). Afyonkarahisar İli Kiraz Bahçelerinde Zararlı Yaprakbüken [Pandemiscerasana (Hübner, 1786) (Lepidoptera: Tortricidae)]’in Doğal Düşmanlarının Belirlenmesi. İç Anadolu Bölgesi 3. Tarım ve Gida Kongresi (26-28 Ekim 2017), Cumhuriyet Üniversitesi, Sivas.

Özdemır, Y. \& Özdemir, M., (2002). Orta Anadolu Bölgesinde Archips türlerinde (Lep.:Tortricidae) saptanan Ichneumonidae (Hym.) türleri. Bitki Koruma Bülteni, 2002, 42 (1-4): 1-7.

Özder, N., (1999). Tekirdağ ilinde kiraz bahçelerinde bulunan doğal düşmanlar ve bunlardan yumurta parazitoiti Trichogramma cacoeciae March.(Hym.: Trichogrammatidae)'nin yaprak büken türlerinde (Lep.: Tortricidae) doğal etkinliği üzerinde araştırmalar. Türkiye 4. Biyolojik Mücadele Kongresi, 26-29 Ocak 1999.

Piekarska-Bonıecka, H., Wilkanıec, B. \& Dolan'Ska-Niedbała, E., (2008). Parasitoids of Ichneumonidae family (Hymenoptera, Apocrita) limiting abundance of rose tortrix moth Archips rosana (L.) in selected orchards in Wielkopolska. Progress in Plant Protection, 48 (4), 1319-1322.

Polat, A. \& Tozlu, G., (2010). Erzurum'da Archips rosana (Lin., 1758) (Lep.: Tortricidae)'nın kısa biyolojisi, konukçuları ve parazitoitleri üzerinde araştırmalar. Türkiye Entomoloji Dergisi, 2010,(4):529-542.

Tezcan, S. \& Okyar, Z., (2004). İzmir ve Manisa İlleri Ekolojik Kiraz Bahçelerinden Toplanan Thyatiridae, Papillionidae, Pieridae, Nymphalidae ve Satyridae (Lepidoptera) Familyalarına Bağlı Türler Üzerinde Bir Değerlendirme. Trakya Univ J Sci, 5(2): 127133.

Ulu, O., (1983). İzmir ve Manisa İlleri Taş Çekirdekli Meyve Ağaçlarında Zarar Yapan Archip' (Cacoecia spp.) (Lepidoptera: Tortricidae) Türleri, Tanımları, Konukçulan, Yayılışlan ve Kısa Biyolojileri Üzerinde Araştırmalar. T.C. Tar. ve Orm. Bak. Zir. Müc. ve Zir. Kar. Gen. Müd., Bornova Böl. Zirai Mücadele Araştırma Enstitüsü Müdürlüğü, Araştırma Serisi No: 45,165s, Ankara.

Ulusoy, M.R., Vatansever, G. \& Uygun, N., (1999). Ulukışla (Niğde) ve Pozantı (Adana) yöresinde kirazlarda zararlı olan türler, doğal düşmanları ve önemlileri üzerindeki gözlemler. Türkiye Entomoloji Dergisi, 23 (2): 111-120.

Ülkümen, L., (1973), Bağ-Bahçe Ziraatı. Atatürk Üniversitesi Yayınları No: 275, Ziraat Fakültesi Yayınları No: 128, Ders Kitapları Serisi No: 22, Erzurum.

Yoldaş, Z., (1994). İki Farklı Avla Beslenen Chrysoperla carnea (Stephens) (Neuroptera: Chrysopidae)'nın Biyolojisi Üzerinde Araştırmalar. Türkiye 3. Biyolojik Mücadele Kongresi Bildirileri (25-28 Ocak 1994), 375-380 s., İzmir. 